\title{
Imaging predictors of procedural and clinical outcome in endovascular acute stroke therapy
}

\author{
Nicholas A. Telischak ${ }^{*}$ and Max Wintermark
}

\begin{abstract}
Acute stroke affects 795,000 people per year in the United States, and eighty-seven percent of these represent ischemic stroke. New level I evidence has created a need for consistent, effective and rapid triage of stroke patients to properly select those who will most benefit from endovascular stroke therapy. This review highlights anatomical factors and imaging signs that are prognostic with respect to stroke outcome and which could aid in the selection of patients that could most benefit from interventional stroke therapies, as well as exclude patients from therapy who are at a high risk of complication.
\end{abstract}

Keywords: Stroke, Endovascular stroke, Perfusion imaging, Clot characteristics, Blood brain permeability, Core infarct

\section{Introduction}

Acute stroke affects 795,000 people per year in the United States, and eighty-seven percent of these represent ischemic stroke. The prevalence of stroke is projected to increase $20.5 \%$ by the year 2030, as a result of an aging population [1]. While intravenous tissue plasminogen activator (tPA) has been a mainstay of stroke therapy since its approval by the Food and Drug Administration in 1996, interventional treatment of stroke provides the best possible chance of a good clinical outcome when patients are appropriately selected, as has recently been borne out by a handful of randomized controlled trials [2-5]. While this wealth of new data is very exciting, predicting which patients will respond best to stroke therapy remains a challenge. In this review, we aim to highlight imaging findings prior to stroke therapy that may predict therapeutic and clinical success.

\section{Clinical trials of endovascular treatment of stroke}

Interventional treatment of stroke denotes any catheterdirected therapy and has progressed from intra-arterial administration of tPA to mechanical clot disruption with a microwire, the MERCI device, suction thrombectomy (e.g. Penumbra), and use of stent-retriever devices including Solitaire and TREVO. Initially the IMS III, SYNTHESIS expansion, and MR RESCUE trials failed to show a clinical benefit to interventional stroke. Lessons learned from

\footnotetext{
* Correspondence: teli@stanford.edu

Department of Neuroradiology, 5047300 Pasteur Drive, Stanford, CA 94305, USA
}

these trials have resulted in recent randomized controlled trials overwhelmingly favoring endovascular stroke therapy. Intra-arterial thrombolysis was originally evaluated in a randomized-controlled trial using the drug prourokinase in the PROACT II trial, which showed $66 \%$ recanalization in patients randomized to treatment, but also showed a relatively high rate of symptomatic intracranial hemorrhage. The clinical outcomes showed no difference in mortality between groups, and an absolute increase in favorable outcome of $15 \%$ in the interventional group, corresponding to a number needed to treat of 7 [6]. The drug used in this trial, urokinase, was pulled by the FDA due to "significant deviations from Current Good Manufacturing Practices" [7].

The IMS III trial randomized 656 participants and showed similar rates of functional independence (mRS 0-2) of $40.8 \%$ and $38.7 \%$ in the endovascular and IV tPA groups, respectively, with a trend toward better outcomes in the endovascular group among patients with National Institute of Health Stroke Scale (NIHSS) >20 [8]. A strong criticism of this trial is that less than half of patients got a CTA resulting in $20 \%$ of patients without a large vessel occlusion being randomized to the interventional arm. Standard dose IV TPA was not given to the majority of patients in the interventional arm. Due to the slow trial recruitment, there were many protocol iterations with many patients receiving interventional therapy with first-generation devices that do not have the same efficacy or safety profile as 
Table 1 Modified Rankin Scale (mRS) for standardized evaluation of clinical outcome after stroke

\begin{tabular}{ll}
\hline $\begin{array}{l}\text { Modified Rankin } \\
\text { Scale (mRS) }\end{array}$ & Clinical Description \\
\hline 0 & No symptoms. \\
1 & No significant disability. Able to carry out all \\
& usual activities despite some symptoms. \\
& Slight disability. Able to look after own affairs \\
& without assistance, but unable to carry out all \\
& previous activities. \\
& Moderate disability. Requires some help, but \\
& able to walk unassisted. \\
& Moderately severe disability. Unable to attend to \\
& own bodily needs without assistance. Unable to \\
& walk unassisted. \\
& Severe disability. Requires constant nursing care \\
& and attention, bedridden, incontinent. \\
& Dead. \\
\hline
\end{tabular}

today's stentrievers (40\% recanalization in IMS III versus $68 \%-80 \%$ recanalization with modern stentrievers) [8].

The SYNTHESIS expansion trial enrolled 362 patients with AIS to IV tPA within $4.5 \mathrm{~h}$ versus IA therapy within $6 \mathrm{~h}$ of symptom onset. No pre-procedural imaging was required (10\% of patients did not have a large vessel occlusion), nor was a lower boundary of NIHSS at presentation defined (nearly half of enrolled patients had NIHSS scores of 10 or less). Once randomized, 165 of 181 patients in the interventional arm received an endovascular procedure, and only 56 of these received mechanical thrombectomy. Additionally, the intervention arm received treatment one hour later on average compared to the IV arm. Success of revascularization was not reported. Despite lack of confirmation of a large vessel occlusion, withholding of IV tPA, and the delivery of IA tPA to patients without a vessel occlusion, there was no increase in death or intracranial hemorrhage compared to IV tPA. Not surprisingly given these shortcomings, the trial failed to show a benefit in 3 month $\mathrm{mRS}$ in the interventional arm [9].

The Mechanical Retrieval and Recanalization of Stroke Clots Using Embolectomy (MR RESCUE) Trial was a multi-center randomized trial comparing standard medical care to interventional stroke therapy in patients presenting within 8-h with a large vessel anterior circulation stroke. All patients received a perfusion $\mathrm{MR}$ or $\mathrm{CT}$ prior to randomization. Interventional stroke therapy was not superior to standard medical care, but this trial did show that patients with revascularization had improved 3-month mRS (3.2 versus 4.1) and lower median absolute infarct growth (9.0 mL vs. $73 \mathrm{~mL}$ ) [10]. Importantly, MR RESCUE included first generation thrombectomy devices only, and achieved a very low reperfusion rate $(27 \%)$ compared with modern trials [10].

Many lessons learned from the shortcomings of these trials have highlighted the attributes of an ideal candidate for stroke intervention: 1) A proximal vessel occlusion that can be reached by an endovascular approach, 2) a small area of core infarction, and 3) viable tissue at risk of infarction if reperfusion is not achieved, the ischemic "penumbra" [11]. This knowledge has resulted in a wealth of recent trials showing overwhelming benefit of endovascular stroke therapy beginning with the MR CLEAN trial from the Netherlands.

MR CLEAN enrolled 500 patients with a confirmed proximal arterial occlusion in the anterior cerebral circulation who could be treated intra-arterially within $6 \mathrm{~h}$ of symptom onset. The majority (89\%) of enrolled patients were treated with IV-tPA prior to endovascular therapy, and in the interventional arm four out of five patients $(81.5 \%)$ were treated with retrievable stent devices resulting in a good rate (58.7\%) of recanalization. Using modified Rankin scale shift at 90 days, the adjusted common odds ratio was 1.67 in favor of the intervention [2].

The REVASCAT trial was halted early citing loss of equipoise after the publication of the MR CLEAN results. REVASCAT randomized 206 patients with a proximal anterior circulation occlusion without a large infarct who could be treated within $8 \mathrm{~h}$ from symptom onset to medical therapy alone (IV tPA) or medical therapy and endovascular therapy with the Solitaire stent retriever. Ischemic core was estimated by ASPECTS, admitting patients only with ASPECTS of 6 to 10; NIHSS was at least 6 for admission into the trial. This trial showed benefit of endovascular stroke therapy, with a common odds ratio of 1.7 in the Rankin shift analysis in favor of endovascular therapy, and $15.5 \%$ absolute difference in the proportion of patients who were functionally independent at 90 days (43.7 \% vs. $28.2 \%$ ) [4].

The ESCAPE trial was halted early after an interim analysis was prompted by the MR CLEAN results. ESCAPE

Table $2 \mathrm{TICl}$ Scoring for assessment of procedural success in acute stroke therapy

\begin{tabular}{ll}
\hline Grade & TICI Score \\
\hline 0 & No Perfusion. \\
1 & $\begin{array}{l}\text { Antegrade reperfusion past the initial occlusion but limited } \\
\text { distal branch filling with little or slow distal reperfusion. }\end{array}$ \\
$2 \mathrm{a}$ & $\begin{array}{l}\text { Antegrade reperfusion of less than half of the occluded target } \\
\text { artery previously ischemic territory (e.g. } 1 \text { major MCA division } \\
\text { and its territory). }\end{array}$ \\
& $\begin{array}{l}\text { Antegrade reperfusion of more than half of the previously } \\
\text { occluded target artery ischemic territory. } \\
3\end{array}$ \\
& $\begin{array}{l}\text { Complete antegrade reperfusion of the previously occluded } \\
\text { target artery without visualized distal occlusion in all distal } \\
\text { branches. }\end{array}$ \\
\hline
\end{tabular}



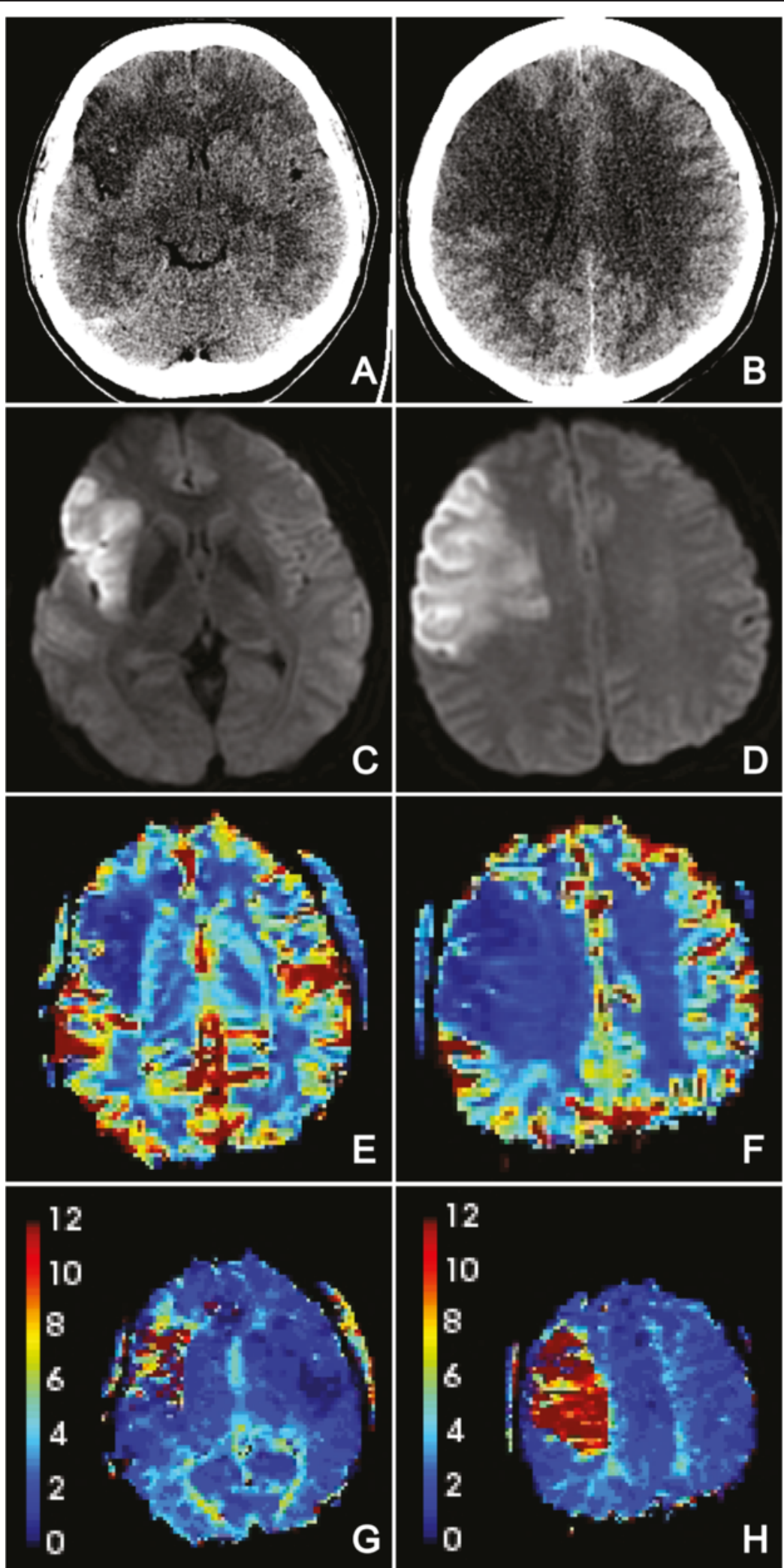

Fig. 1 (See legend on next page.) 
(See figure on previous page.)

Fig. 1 Large ischemic core in a 37-year-old female who awoke with right gaze preference and left sided-weakness. Axial non-contrast computed tomography (CT) images at the level of the basal ganglia (a) and through the centrum semiovale (b) show hypodensity and loss of grey-white differentiation of the right insular cortex, putamen, and right frontal grey matter. This is similarly shown by axial diffusion weighted images (c, d). Cerebral blood volume (CBV) map from the perfusion CT show decreased CBV corresponding to those territories consistent with a large core of completed infarct (e, f). The Tmax maps demonstrate a matched perfusion deficit $(\mathbf{g}, \mathbf{h})$

recruited 316 patients with a proximal anterior circulation occlusion and randomized to standard of care with IV tPA vs. standard of care plus endovascular treatment with thrombectomy devices up to $12 \mathrm{~h}$ from symptom onset. Patients with large infarct (Alberta Stroke Program Early CT Score, ASPECTS $<6)$ or poor collaterals $(<50 \%$ filling of pial collaterals on CTA) were excluded. This study showed both an improvement in mRS at 90 days in the interventional arm of $53.0 \%$ vs. $29.3 \%$ as well as a decreased mortality in the interventional arm of $10.4 \%$ vs. $19.0 \%$ [5].

The EXTEND-IA trial was also stopped early once the results of MR CLEAN became available, after recruitment of 70 patients who were receiving IV tPA within $4.5 \mathrm{~h}$ from symptom onset to interventional treatment with the Solitaire stent-retriever device or to continuation of IV tPA alone. Eligible patients were selected with perfusion-CT and CT-angiogram to have a proximal anterior circulation arterial occlusion and an ischemic core of less than $70 \mathrm{~mL}$. Compared with IV tPA alone, endovascular therapy resulted in a significantly higher probability of reperfusion ( $89 \%$ vs. $34 \%$ ), and this translated to a significant clinical benefit with more patients in the interventional arm (71\% vs. $40 \%$ ) achieving functional independence (mRS 0-2) at 90 days [3].

The SWIFT PRIME study enrolled patients with a NIHSS $>8$ resulting from a proximal anterior circulation arterial occlusion and utilized perfusion-CT with automated software to compute the volume of core infarct selecting patients with a core $<50 \mathrm{cc}$ (later modified to read baseline evidence of a moderate/large core as defined by ASPECTS $<6$ ). Patients with a Tmax lesion of $>100 \mathrm{cc}$ were excluded (see malignant perfusion profile, below). The treatment window in SWIFT PRIME was $6 \mathrm{~h}$. Again, this trial showed a benefit of endovascular therapy showing a number needed to treat of only 2.6 for an improved disability outcome, and of only 4 patients for one additional patient to be functionally independent at 90 days [12].

Beyond the proven clear benefit of endovascular stroke therapy, there are lessons to be learned. Three studies that showed the highest frequency of functional independence were the SWIFT PRIME (60\%), the ESCAPE trial (53 \%) and the EXTEND IA trial (71 \%). This likely reflects commonalities among these trials including fast time to endovascular therapies, exclusion of patients with large core infarcts on the basis of advanced imaging, and higher rates of reperfusion in the endovascular arms. Advanced imaging clearly plays a role in patient selection for endovascular stroke therapy; the goal of this paper is to review predictive signs and measures of advanced imaging in acute stroke.

\section{Outcome measures in endovascular stroke therapy}

Outcome measures in endovascular acute stroke therapy may be graded with clinical metrics (e.g. $\mathrm{mRS}$ at 90 days) $[13,14]$, and with imaging metrics (e.g. TICI reperfusion score) [15]. These are well reviewed elsewhere and are summarized in Table 1 and Table 2.

There are numerous fixed clinical variables that impact the outcome of a stroke patient after reperfusion therapy, including presentation NIHSS, baseline functional status, time from stroke onset to reperfusion, patient age, patient comorbidities, etc. In this paper, we focus on imaging findings that can predict procedural success and clinical outcome.

\section{Results: Imaging predictors of good outcomes in endovascular stroke therapy}

\section{Side of occlusion}

The laterality of the stroke has a great effect on patient outcome, with dominant hemisphere strokes having a greater impact per volume of infarct than a nondominant hemisphere stroke. In a study relating DWI lesion volume to poor outcome $(\mathrm{mRS}>2)$, the $95 \%$ specificity lesion volume was $51.8 \mathrm{~mL}$ for the left hemisphere compared to $98.5 \mathrm{~mL}$ for right hemisphere involvement, indicating that non-dominant hemisphere strokes are better tolerated [16]. While some of this difference relates to an inherent bias of the NIHSS scoring towards dominant hemisphere stroke, it is clear that a dominant hemisphere infarct portends a worse prognosis.

\section{Ischemic core estimation}

The size of the completed infarct when a patient presents with a stroke represents irrecoverable damage and therefore more than success of recanalization sets the stage for how much recovery can be expected [17]. Ischemic core size is an independent predictor of outcome after stroke, whether measured by CT or DWI MR (Fig. 1) [18-21]. In a retrospective study, good outcome (mRS 0-2) occurred with average lesion volumes of $16.3 \mathrm{~mL}$ whereas the average lesion size in poor outcome $(\mathrm{mRS}>2)$ was $63.4 \mathrm{~mL}$ 

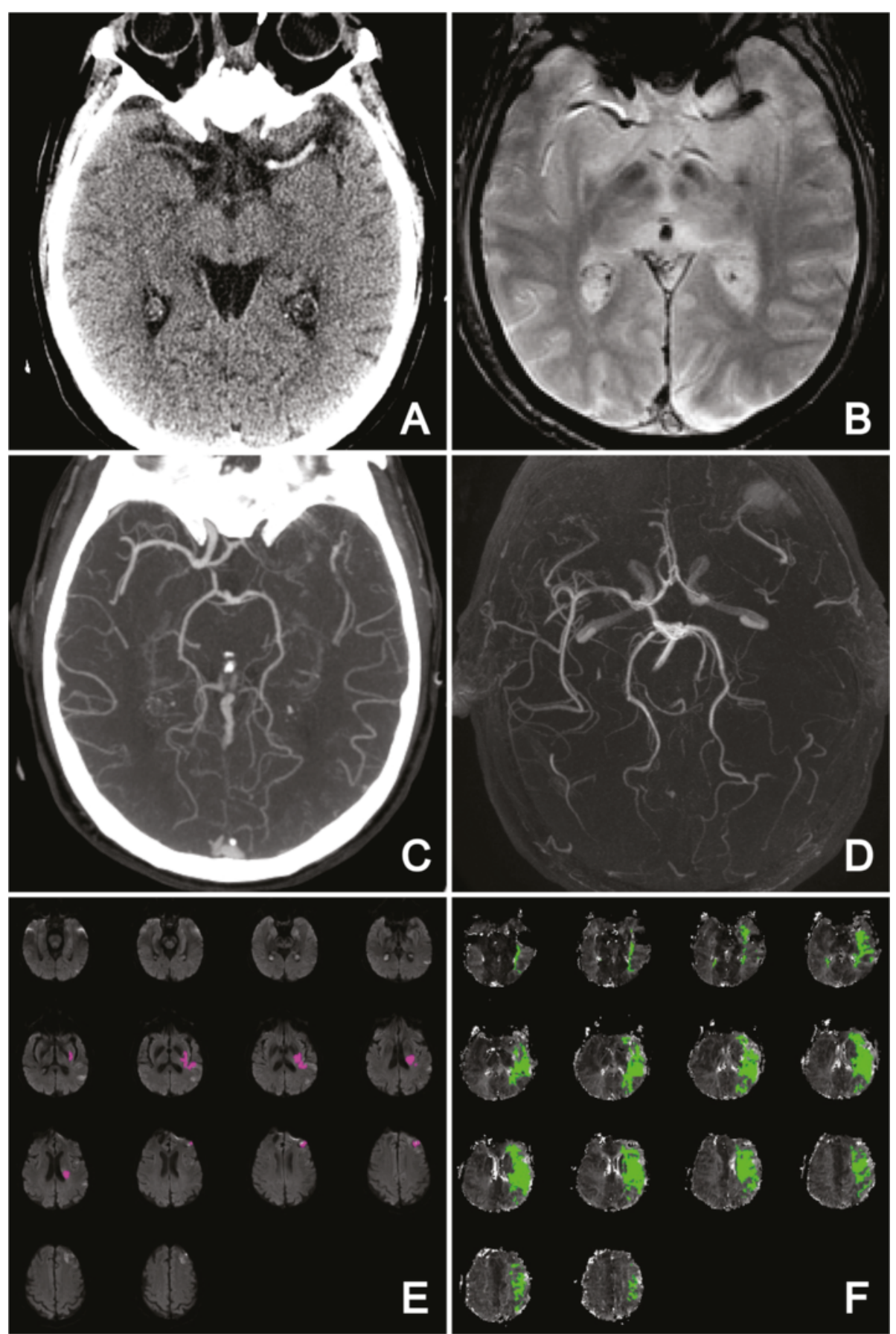

Fig. 2 Dense middle cerebral artery (MCA) sign with an ischemic penumbra in a 68-year-old male with acute stroke. Non-contrast computed tomography (CT) demonstrates a dense left MCA with long length of thrombus (a). This manifests "blooming" on gradient recalled echo (GRE, b) magnetic resonance imaging. CT angiography (CTA) shows a left carotid terminus occlusion extending into the left middle cerebral artery (c), with a better depiction of collaterals than can be seen on the time-of-flight magnetic resonance angiogram (MRA, d). Diffusion weighted MR image (DWI, e) and perfusion weighted MRI Tmax map with colorized overlay representing the infarcted core (pink, e) and the territory at risk (green, $\mathbf{f}$ ), here showing a favorable perfusion pattern with a small ischemic core and large penumbra

again demonstrating the link between lesion size at presentation and outcome [16]. When measured by MRI at $48 \mathrm{~h}$, the infarct volume is an independent predictor of outcome [18]. The estimation of ischemic core by DWI during acute stroke is highly correlative with final stroke volume, with normalization of brain tissue previously showing abnormal DWI signal ("DWI reversal") representing an unlikely event. When DWI reversal does occur it is not of sufficient 
size to meaningfully alter the degree of diffusion-perfusion mismatch [22].

Because MRI is difficult to obtain at many centers alternate methods have been devised to estimate ischemic core with CT. The Alberta Stroke Program Early CT Score (ASPECTS) divides the brain into 10 territories with points removed for loss of grey matter-white matter differentiation in each territory based on a non-contrast CT evaluation [23]. This score has been shown repeatedly to correlate with outcome; for instance when applied to the National Institute of Neurological Disorders and Stroke (NINDS) cohort, ASPECTS 8-10 group had a greater benefit from IV thrombolysis and a trend toward reduced mortality [24]. In the original study ASPECTS score of 7 or below demarcated good from poor outcomes [23]. The rate of change of ASPECTS score in patients transferred to a comprehensive stroke center having already undergone a CT scan at an outside hospital is likely a reflection of collateral perfusion and is also predictive of outcome [25].

Perfusion CT (PCT) imaging is used at many stroke centers to triage patients to appropriate therapy because it is fast to obtain and nearly universally available. The primary goal of perfusion imaging is to differentiate ischemic core from the penumbra [26]. Within an ischemic core both cerebral blood flow (CBF) and cerebral blood volume (CBV) are lowered; CBV is the most accurate predictor of the core infarct [27]. A trial investigating whether PCT can predict response to recanalization, Computed Tomography Perfusion to Predict Response to Recanalization in Ischemic Stroke Project (CRISP), is ongoing [28].

\section{Clot location}

The location of the occluded vessel has an effect both on success of revascularization but also on clinical outcomes. Large vessel occlusion, defined in one study as vertebral, basilar, internal carotid, proximal (M1 segment) middle cerebral and proximal (A1 segment) anterior cerebral artery occlusion, correlates to worse outcome. Specifically, the odds ratio for mortality is 4.5 and the odds ratio of good outcome ( $\mathrm{mRS} \leq 2)$ is 0.33 in patients with a large vessel occlusion compared to those without [29].

In patients treated with IV TPA, the rates of complete recanalization for ICA terminus, proximal MCA, and distal MCA are $5 \%, 10 \%$ and $22 \%$, respectively [30]. In the SWIFT trial, the ICA, M1 MCA, and M2 MCA made up $21 \%, 66 \%$, and $10 \%$, respectively, of patients randomized to the Solitaire device with overall recanalization of $69 \%$ as assessed by the core laboratory [31]. In TREVO2, rates of ICA, M1 and M2 enrollment were $16 \%, 60 \%$, and $16 \%$, respectively, with overall recanalization $(\mathrm{TICI} \geq 2)$ of $86 \%$ [32]. More proximal occlusions are therefore much less likely to respond to IV compared to IA therapy. In the DEFUSE2 trial, using largely first-generation thrombectomy devices, ICA and MCA occlusions were revascularized with similar success (61\% and $59 \%$, respectively) with similar proportions of good clinical outcome after revascularization of $65 \%$ for ICA recanalization and $63 \%$ for MCA recanalization [33].

Even when applied to the M1 segment, patients harboring proximal M1 segment MCA lesions are less likely to have a good functional outcome compared to distal M1 segment MCA lesions (8 \% vs. $39 \%$ ), and are more likely to sustain a basal ganglia infarct comprising the internal capsule ( $83 \%$ vs. $11 \%$ ) [34]. A similar study examined patient outcome based on location of hyperdense MCA sign, and showed improved clinical outcome in distal as compared with proximal sites of occlusion (85\% vs. $15 \%$ mRS 0-2) [35].

\section{Clot characteristics}

Thrombus is most commonly the cause of ischemic stroke, but not every thrombus is the same. Thrombus subtype has been stratified into platelet-rich and red blood cell-rich varieties, and this distinction has been shown to have an effect on success of tPA and on interventional stroke therapy [36]. Surrogate markers of clot composition include density on non-contrast CT, and the degree of blooming artifact on GRE MR images (Fig. 2). Dense clots on CT and blooming clots on GRE MRI both imply a red blood cell predominant composition. Red cell predominant clots infer a favorable response to both IV and IA stroke therapies compared with clots of lower density or without GRE blooming artifact [37].

The length of thrombus, also described as clot burden, has been shown to predict likelihood of recanalization, as well as final stroke outcome. In one study, no thrombus exceeding 8-mm in length resulted in recanalization after treatment with IV TPA [38]. Another study in which 54\% of patients received IV tPA and the other $46 \%$ received IV tPA plus IA therapy, recanalization was achieved $85 \%$ of the time for thrombi $<10 \mathrm{~mm}, 37.5 \%$ for thrombi 10 $20 \mathrm{~mm}$, and in no cases for thrombi $>20 \mathrm{~mm}$, demonstrating that a longer thrombus is more resistant to both IV and IA therapies [39]. When a "clot burden" score is

Table 3 ASITN/SIR Collateral flow grading system

\begin{tabular}{ll}
\hline Grade 0 & No collaterals visible to the ischemic site \\
Grade 1 & $\begin{array}{l}\text { Slow collaterals to the periphery of the ischemic site } \\
\text { with persistence of some of the defect }\end{array}$ \\
Grade 2 & $\begin{array}{l}\text { Rapid collaterals to the periphery of ischemic site } \\
\text { with persistence of some of the defect and to only } \\
\text { a portion of the ischemic territory }\end{array}$ \\
Grade 3 & $\begin{array}{l}\text { Collaterals with slow but complete angiographic blood } \\
\text { flow of the ischemic bed by the late venous phase } \\
\text { Grade } 4\end{array}$ \\
& $\begin{array}{l}\text { Complete and rapid collateral blood flow to the vascular } \\
\text { bed in the entire ischemic territory by retrograde } \\
\text { perfusion }\end{array}$
\end{tabular}



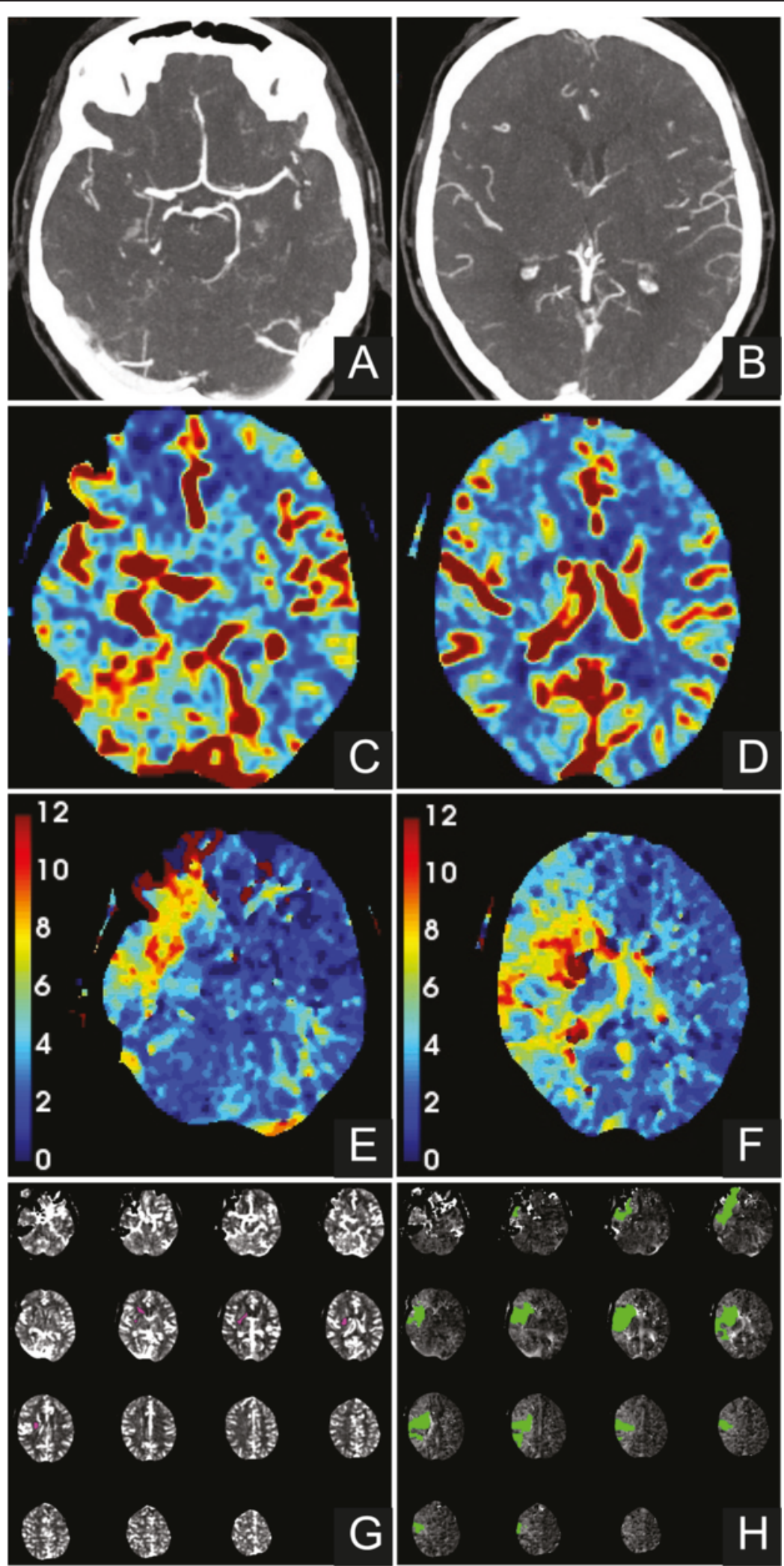

Fig. 3 (See legend on next page.) 
(See figure on previous page.)

Fig. 3 Favorable collaterals in a 67-year-old with acute right MCA occlusion. Axial maximum intensity projection (MIP) of the CTA show a right M1 segment MCA occlusion (a) with excellent collateral filling of the affected territory (a, b). Correlative CTP shows no CBV evidence of a completed core infarct $(\mathbf{c}, \mathbf{d})$. A large ischemic penumbra is evident on the Tmax maps $(\mathbf{e}, \mathbf{f})$. Colorized threshold maps demonstrate a small region of core infarct (pink, $\mathbf{g}$ ) with a relatively large territory at risk (green, $\mathbf{h}$ )

allocated for thrombotic occlusion of vascular territories, increasing clot burden is associated with both worse functional outcome as well as with larger final infarct as assessed by ASPECTS score [40]. Looking forward, imaging may serve as a tool to better define clot constituents and help guide treatment decisions based on probability of success for a given clot composition.

\section{Collateral scoring}

In ischemic stroke, neuronal loss occurs at an average rate of 1.9 million per minute [41]. While this number is grossly simplified, it speaks to the exquisite sensitivity of a neuron to oxygen debt. It therefore stands to reason that collateral flow is a critical factor in determining both the rate of stroke completion and the extent of involvement of the affected hemisphere. A recent review cited 63 different methods of assessing collateral flow, however the most commonly used method, developed by the American Society of Interventional and Therapeutic Neuroradiology (ASITN) and the Society of Interventional Radiology (SIR) is summarized in Table 3 [42].

High quality collaterals have been shown to be independent predictors of both favorable outcome and recanalization (Fig. 3) [43-46]. When applied to stroke, a malignant profile representing a complete lack of collateral vessels in the affected territory, is a discriminator of lesion volume $>100 \mathrm{~mL}$ (itself a strong predictor of outcome), and of being functionally dependent $(\mathrm{mRS} \geq 3)$ at 3 months [47].

Good collaterals are a strong predictor of recanalization; conversely patients with poor collaterals are less likely to achieve recanalization and more likely to have hemorrhagic transformation $[48,49]$. In the ENDOSTROKE study, better collateral vessels (ASITN/SIR grades of 0 or 1, 2, and 3 or 4) were associated with higher reperfusion rates $(21 \%$, $48 \%$, and $77 \%$ ), a higher proportion of infarcts smaller than one-third of the MCA territory (32\%, $48 \%$, and $69 \%$ ), and a higher proportion of good clinical outcome (11\%, $35 \%$, and $49 \%$ [ [50].

In the ESCAPE trial of endovascular stroke therapy, in addition to proof of small infarct core and proximal vessel occlusion, patients were selected on the basis of a moderate to good collateral score, which has also been shown to be an independent predictor of outcome after stroke $[5,51]$. Good patient selection in this trial clearly contributed to the favorable treatment results, highlighting the value of collateral scoring.

\section{Penumbra imaging}

Estimate of the ischemic penumbra in acute stroke in relation to the core infarct is a critical piece of information when triaging candidates for interventional stroke therapy. While ischemic penumbra is present in $90 \%$ to $100 \%$ of patients with anterior circulation stroke in a three hour window, $75 \%$ to $80 \%$ continue to have some degree of penumbral tissue at $6 \mathrm{~h}$ [26]. Selecting patients with preserved tissue at risk prevents futile reperfusion of infarcted tissue and improves outcomes in stroke therapy [2-5]. Indeed, recent trials that selected patients for endovascular stroke therapy with perfusion imaging show the largest benefit $[2,3]$. This estimate may be made clinically using the NIHSS as a surrogate marker of ischemia, but using PCT imaging adds specificity and reproducibility to this estimate (Fig. 4). Penumbral information as assessed by PCT provides information that cannot be inferred clinically, and is an independent predictor of stroke outcome. An important point with respect to perfusion imaging is a finding termed the malignant profile, which denotes a large lesion with markedly delayed perfusion as defined by a DWI core $>100 \mathrm{~mL}$ or a perfusion-weighted image lesion of $100 \mathrm{~mL}$ or more with Tmax delay of $8 \mathrm{~s}$ or more. The malignant profile is associated with poor outcome and a higher rate of symptomatic intracranial hemorrhage after interventional stroke therapy (Fig. 5) [52].

\section{White matter injury}

Diffusion tensor imaging (DTI) allows visualization of white matter tracts, the injury of which has prognostic value in acute stroke. For instance, the integrity of the corticospinal tract as assessed by MRI can predict the probability of motor recovery after corona radiata stroke [53-55]. In the acute stage, diffusion tractography predicted motor function at 90 days better than clinical scores [55].

\section{Blood-brain barrier (BBB) permeability}

Symptomatic intracranial hemorrhage is a complication of endovascular stroke therapy with an incidence ranging from $0-7.7 \%$ in recent trials [2-5]. This can have important consequences for final outcome after endovascular stroke therapy and therefore it is important to have imaging metrics to prospectively exclude patients who are at a high risk of hemorrhage from endovascular therapies. The hyperintense acute reperfusion marker (HARM) is an early marker of $\mathrm{BBB}$ breakdown, observed as hyperintense signal seen 

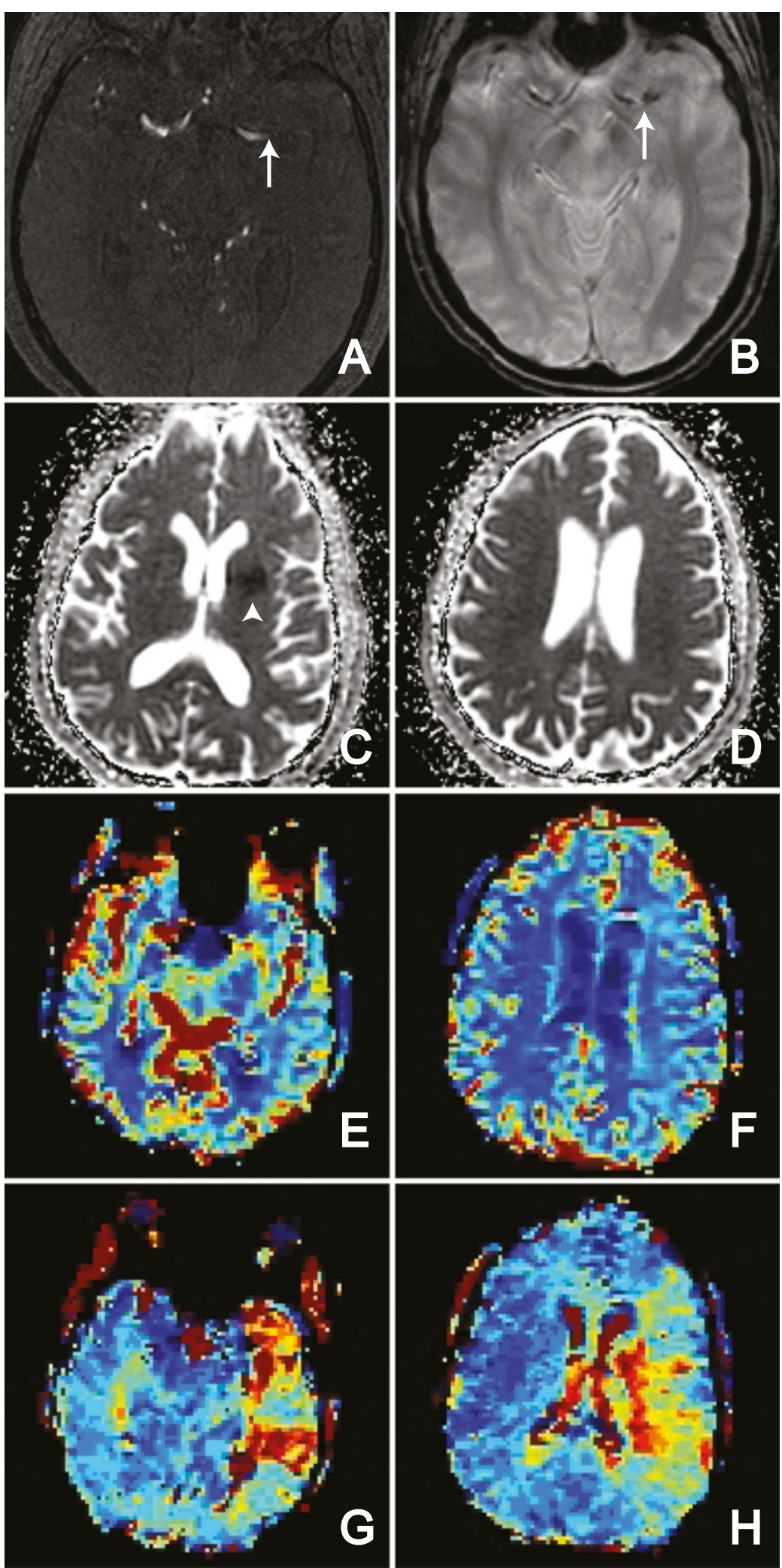

Fig. 4 (See legend on next page.) 
(See figure on previous page.)

Fig. 4 Large ischemic penumbra with small core infarct in a 73 year-old with acute stroke. MRA shows acute M1 segment MCA vessel cutoff (arrow, a). Blooming artifact localizes to the occlusive thrombus on the GRE image (arrow, b). Apparent diffusion coefficient (a, d, c) map (c, d) demonstrating a small region of core infarct (arrowhead). CBV maps from the PCT show no region of decrease to suggest a large core infarct $(\mathbf{e}, \mathbf{f})$. Ischemic penumbra comprises the majority of the left MCA territory on the Tmax maps $(\mathbf{g}, \mathbf{h})$
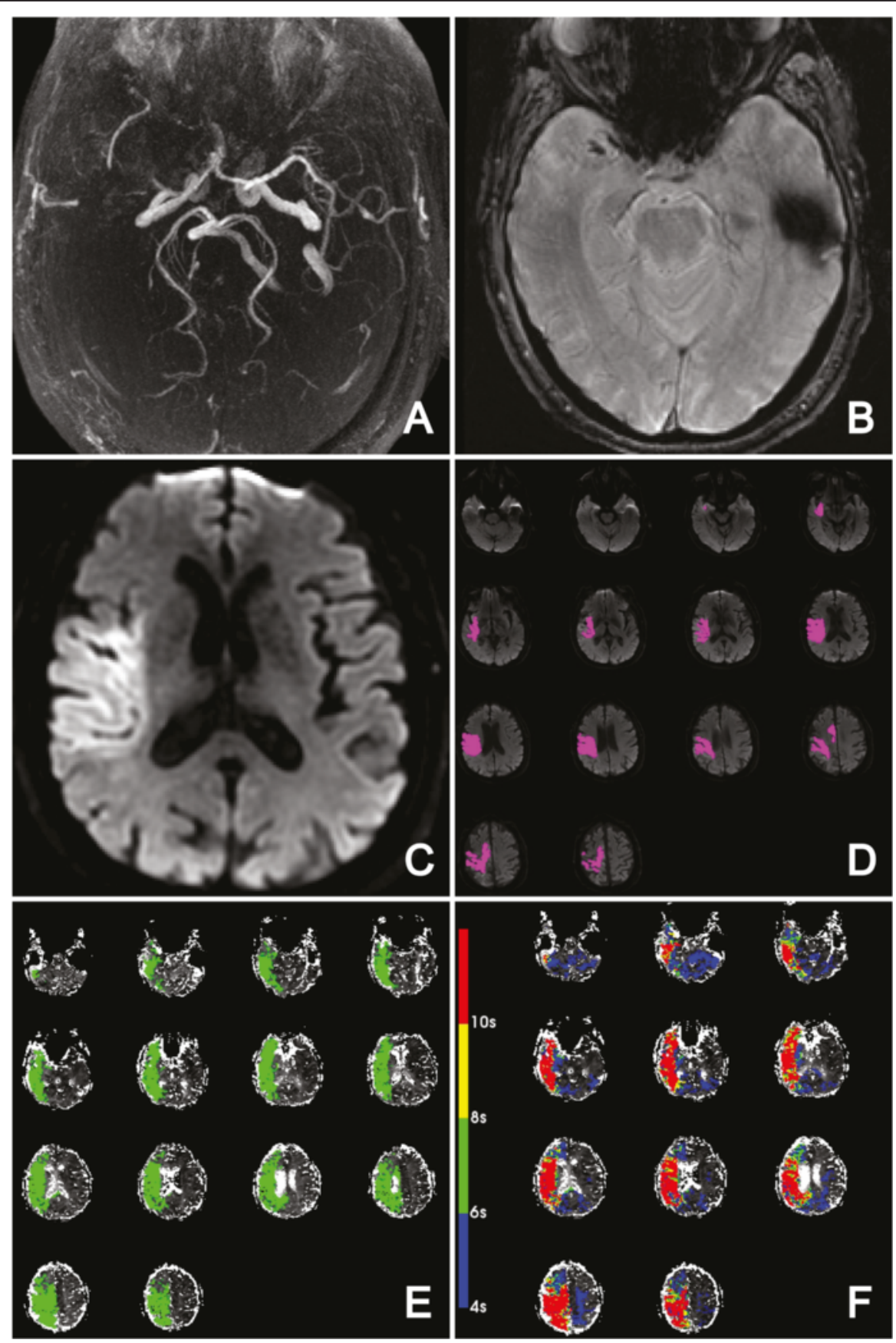

Fig. 5 Malignant perfusion profile in an 82-year-old with a right MCA syndrome. MRA showing a right M1 segment MCA occlusion (a). GRE image demonstrates blooming from thrombus at the site of occlusion (b, arrow). DWI image demonstrates a moderate-sized ischemic core (c), which is colorized on the perfusion map (pink, d). The ischemic penumbra is larger than the ischemic core (green, e) but in this instance is notable for a large volume of Tmax > 10s consistent with a malignant perfusion profile (f) 
on FLAIR hours to days after gadolinium administration believed to be caused by accumulation of contrast material in the CSF spaces, and is associated with higher rates of hemorrhagic transformation of stroke [56]. Unfortunately since HARM is seen hours to days after an initial MRI, this is not useful for triage of interventional therapies. Blood brain barrier permeability increases with increasing neuronal injury as a result of ischemia-induced break down of tight junctions, and can be measured with perfusion imaging as expressed by a permeability surface area product (PS). This tool can prospectively stratify patients into those who will or will not go on to develop hemorrhagic conversion using a PS threshold of $0.23 \mathrm{~mL} / \mathrm{min} / 100 \mathrm{~g}$ [57]. Another study observed an odds ratio of 28 for hemorrhagic transformation discriminating with a PS of $>0.84 \mathrm{~mL} / 100 \mathrm{~g} / \mathrm{min}$ [58]. While not in widespread use, this information is in theory readily available in centers that triage stroke with perfusion imaging.

\section{Conclusion}

Level I evidence showing a powerful benefit for endovascular stroke therapy makes this an exciting time for endovascular stroke therapy. On the other hand this evidence has created a need for consistent, effective and rapid triage of stroke patients to properly select those who will most benefit from endovascular stroke therapy. Recent trials have highlighted the need to select patients for endovascular stroke therapy based on the presence of a proximal arterial occlusive lesion, a small-to-moderate sized core infarct, and evidence of ischemic penumbra. While this is simple and quick to perform, it is not nuanced and many other useful imaging predictors of stroke outcome are not taken into consideration in such a simple model. This review has highlighted specific anatomical factors, imaging signs, and stroke physiology that have predictive value in the setting of the triage of a patient presenting with acute stroke. Looking forward, these imaging-specific factors could be included along with demographic factors such as patient age and baseline functional status in a more comprehensive prognostic model to assist in the triage of stroke patients.

\section{Competing interests}

The authors declare that they have no competing interests.

\begin{abstract}
Authors' contributions
MW and NT each contributed to text. All authors read and approved the final manuscript.
\end{abstract}

Received: 9 June 2015 Accepted: 30 June 2015

Published online: 24 November 2015

\section{References}

1. Go AS, Mozaffarian D, Roger VL, Benjamin EJ, Berry JD, Blaha MJ, et al. Heart disease and stroke statistics-2014 update: a report from the American Heart Association. Circulation. 2014;129:e28-292.

2. Berkhemer OA, Fransen PS, Beumer D, van den Berg LA, Lingsma HF, Yoo $\mathrm{AJ}$, et al. A randomized trial of intraarterial treatment for acute ischemic stroke. The New England journal of medicine. 2015;372:11-20.

3. Campbell BC, Mitchell PJ, Kleinig TJ, Dewey HM, Churilov L, Yassi N, et al. Endovascular therapy for ischemic stroke with perfusion-imaging selection. The New England journal of medicine. 2015;372:1009-18.

4. Jovin TG, Chamorro A, Cobo E, de Miquel MA, Molina CA, Rovira A, et al. Thrombectomy within 8 Hours after Symptom Onset in Ischemic Stroke. New Engl J Med. 2015;372:2296-2306.

5. Goyal M, Demchuk AM, Menon BK, Eesa M, Rempel JL, Thornton J, et al. Randomized assessment of rapid endovascular treatment of ischemic stroke. New Engl J Med. 2015;372:1019-30.

6. Furlan A, Higashida R, Wechsler L, Gent M, Rowley H, Kase C, et al. Intra-arterial Prourokinase for Acute Ischemic Stroke. Jama. 1999;282:2003.

7. U.S. Dept. of Health and Human Services. [http://www.fda.gov/drugs/ developmentapprovalprocess/howdrugsaredevelopedandapproved/ approvalapplications/therapeuticbiologicapplications/ucm113568.htm]

8. Broderick JP, Palesch YY, Demchuk AM, Yeatts SD, Khatri P, Hill MD, et al. Endovascular therapy after intravenous t-PA versus t-PA alone for stroke. New Engl J Med. 2013;368:893-903.

9. Ciccone A, Valvassori L, Nichelatti M, Sgoifo A, Ponzio M, Sterzi R, et al. Endovascular treatment for acute ischemic stroke. New Engl J Med. 2013;368:904-13.

10. Kidwell CS, Jahan R, Gornbein J, Alger JR, Nenov V, Ajani Z, et al. A trial of imaging selection and endovascular treatment for ischemic stroke. New Engl J Med. 2013;368:914-23.

11. Heit JJ, Wintermark M. Imaging selection for reperfusion therapy in acute ischemic stroke. Current treatment options in neurology. 2015;17:332.

12. Saver JL, Goyal M, Bonafe A, Diener HC, Levy El, Pereira VM, et al. Solitaire with the Intention for Thrombectomy as Primary Endovascular Treatment for Acute Ischemic Stroke (SWIFT PRIME) trial: protocol for a randomized, controlled, multicenter study comparing the Solitaire revascularization device with IV tPA with IV tPA alone in acute ischemic stroke. Int J Stroke. 2015;10:439-48.

13. Rankin J. Cerebral vascular accidents in patients over the age of 60. II. Prognosis. Scot Med J. 1957;2:200-15.

14. Farrell B, Godwin J, Richards S, Warlow C. The United Kingdom transient ischaemic attack (UK-TIA) aspirin trial: final results. J Neurol Neurosurg Psychiatr. 1991;54:1044-54.

15. Gerber JC, Miaux YJ, von Kummer R. Scoring flow restoration in cerebral angiograms after endovascular revascularization in acute ischemic stroke patients. Neuroradiology. 2015;57:227-40.

16. Schaefer PW, Pulli B, Copen WA, Hirsch JA, Leslie-Mazwi T, Schwamm LH, et al. Combining MRI with NIHSS thresholds to predict outcome in acute ischemic stroke: value for patient selection. AJNR Am J Neuroradiol. 2015;36:259-64.

17. Zaidi SF, Aghaebrahim A, Urra X, Jumaa MA, Jankowitz B, Hammer M, et al. Final infarct volume is a stronger predictor of outcome than recanalization in patients with proximal middle cerebral artery occlusion treated with endovascular therapy. Stroke; a journal of cerebral circulation.2012;43:3238-44.

18. Thijs VN, Lansberg MG, Beaulieu C, Marks MP, Moseley ME, Albers GW. Is early ischemic lesion volume on diffusion-weighted imaging an

independent predictor of stroke outcome? A multivariable analysis. Stroke; a journal of cerebral circulation. 2000;31:2597-602.

19. Saver JL, Johnston KC, Homer D, Wityk R, Koroshetz W, Truskowski LL, et al. Infarct volume as a surrogate or auxiliary outcome measure in ischemic stroke clinical trials. The RANTTAS Investigators. Stroke; a journal of cerebral circulation. 1999;30:293-8.

20. Vogt G, Laage R, Shuaib A, Schneider A, Collaboration V. Initial lesion volume is an independent predictor of clinical stroke outcome at day 90: an analysis of the Virtual International Stroke Trials Archive (VISTA) database. Stroke; a journal of cerebral circulation. 2012;43:1266-72.

21. Parsons MW, Christensen S, McElduff P, Levi CR, Butcher KS, De Silva DA, et al. Pretreatment diffusion- and perfusion-MR lesion volumes have a crucial influence on clinical response to stroke thrombolysis. J Cerebr Blood Flow Metabol. 2010;30:1214-25. 
22. Campbell BC, Purushotham A, Christensen S, Desmond PM, Nagakane $Y$, Parsons MW, et al. The infarct core is well represented by the acute diffusion lesion: sustained reversal is infrequent. J Cerebr Blood Flow Metabol. 2012;32:50-6.

23. Barber PA, Demchuk AM, Zhang J, Buchan AM. Validity and reliability of a quantitative computed tomography score in predicting outcome of hyperacute stroke before thrombolytic therapy. The Lancet. 2000:355:1670-4.

24. Puetz V, Dzialowski I, Hill MD, Demchuk AM. The Alberta Stroke Program Early CT Score in clinical practice: what have we learned? Int J Stroke. 2009;4:354-64

25. Sun CH, Connelly K, Nogueira RG, Glenn BA, Zimmermann S, Anda K, et al. ASPECTS decay during inter-facility transfer predicts patient outcomes in endovascular reperfusion for ischemic stroke: a unique assessment of dynamic physiologic change over time. Journal of Neurointerventional Surgery. 2015;7:22-6.

26. Wintermark M. Brain perfusion- $\subset T$ in acute stroke patients. Eur Radiol Suppl 2005;15:d28-31.

27. Wintermark M, Flanders AE, Velthuis B, Meuli R, van Leeuwen M, Goldsher D, et al. Perfusion-CT assessment of infarct core and penumbra: receiver operating characteristic curve analysis in 130 patients suspected of acute hemispheric stroke. Stroke; a journal of cerebral circulation. 2006;37:979-85.

28. Computed Tomography Perfusion (CTP) to Predict Response to Recanalization in Ischemic Stroke Project (CRISP). [https://clinicaltrials.gov/ct2/show/ NCT01622517]

29. Smith WS, Lev MH, English JD, Camargo EC, Chou M, Johnston SC, et al. Significance of large vessel intracranial occlusion causing acute ischemic stroke and TIA. Stroke; a journal of cerebral circulation. 2009;40:3834-40.

30. Mendonca N, Rodriguez-Luna D, Rubiera M, Boned-Riera S, Ribo M, Pagola J, et al. Predictors of tissue-type plasminogen activator nonresponders according to location of vessel occlusion. Stroke; a journal of cerebral circulation. 2012:43:417-21.

31. Saver JL, Jahan R, Levy El, Jovin TG, Baxter B, Nogueira RG, et al. Solitaire flow restoration device versus the Merci Retriever in patients with acute ischaemic stroke (SWIFT): a randomised, parallel-group, non-inferiority trial. The Lancet. 2012;380:1241-9.

32. Nogueira RG, Lutsep HL, Gupta R, Jovin TG, Albers GW, Walker GA, et al. Trevo versus Merci retrievers for thrombectomy revascularisation of large vessel occlusions in acute ischaemic stroke (TREVO 2): a randomised trial. The Lancet. 2012;380:1231-40.

33. Lemmens R, Mlynash M, Straka M, Kemp S, Bammer R, Marks MP, et al. Comparison of the response to endovascular reperfusion in relation to site of arterial occlusion. Neurology. 2013;81:614-8.

34. Behme D, Kowoll A, Weber W, Mpotsaris A. M1 is not M1 in ischemic stroke: the disability-free survival after mechanical thrombectomy differs significantly between proximal and distal occlusions of the middle cerebral artery M1 segment. Journal of Neurointerventional Surgery. 2014;7:559-563.

35. Man S, Hussain MS, Wisco D, Katzan IL, Aoki J, Tateishi Y, et al. The location of pretreatment hyperdense middle cerebral artery sign predicts the outcome of intraarterial thrombectomy for acute stroke. J Neuroimaging. 2015;25:263-8.

36. Moftakhar P, English JD, Cooke DL, Kim WT, Stout C, Smith WS, et al. Density of thrombus on admission $C T$ predicts revascularization efficacy in large vessel occlusion acute ischemic stroke. Stroke; a journal of cerebral circulation. 2013:44:243-5.

37. Liebeskind DS, Sanossian N, Yong WH, Starkman S, Tsang MP, Moya AL, et al. $\mathrm{CT}$ and MRI early vessel signs reflect clot composition in acute stroke. Stroke; a journal of cerebral circulation. 2011:42:1237-43.

38. Riedel $\mathrm{CH}$, Zimmermann P, Jensen-Kondering $U$, Stingele R, Deuschl G, Jansen $\mathrm{O}$. The importance of size: successful recanalization by intravenous thrombolysis in acute anterior stroke depends on thrombus length. Stroke; a journal of cerebral circulation. 2011:42:1775-7.

39. Shobha N, Bal S, Boyko M, Kroshus E, Menon BK, Bhatia R, et al. Measurement of length of hyperdense MCA sign in acute ischemic stroke predicts disappearance after IV tPA. J Neuroimaging. 2014;24:7-10.

40. Puetz V, Dzialowski I, Hill MD, Subramaniam S, Sylaja PN, Krol A, et al. Intracranial thrombus extent predicts clinical outcome, final infarct size and hemorrhagic transformation in ischemic stroke: the clot burden score. Int J Stroke. 2008:3:230-6.

41. Saver JL. Time is brain-quantified. Stroke; a journal of cerebral circulation 2006:37:263-6.
42. Higashida RT, Furlan AJ, Roberts H, Tomsick T, Connors B, Barr J, et al. Trial design and reporting standards for intra-arterial cerebral thrombolysis for acute ischemic stroke. Stroke; a journal of cerebral circulation. 2003;34:e109-37.

43. Kucinski T, Koch C, Eckert B, Becker V, Kromer H, Heesen C, et al. Collateral circulation is an independent radiological predictor of outcome after thrombolysis in acute ischaemic stroke. Neuroradiology. 2003;45:11-8.

44. Bang OY, Saver JL, Kim SJ, Kim GM, Chung CS, Ovbiagele B, et al. Collateral flow predicts response to endovascular therapy for acute ischemic stroke. Stroke; a journal of cerebral circulation. 2011;42:693-9.

45. Maas MB, Lev MH, Ay H, Singhal AB, Greer DM, Smith WS, et al. Collateral vessels on $C T$ angiography predict outcome in acute ischemic stroke. Stroke; a journal of cerebral circulation. 2009:40:3001-5.

46. McVerry F, Liebeskind DS, Muir KW. Systematic review of methods for assessing leptomeningeal collateral flow. AJNR Am J Neuroradiol. 2012;33:576-82.

47. Souza LC, Yoo AJ, Chaudhry ZA, Payabvash S, Kemmling A, Schaefer PW, et al. Malignant CTA collateral profile is highly specific for large admission DWI infarct core and poor outcome in acute stroke. AJNR Am J Neuroradiol. 2012;33:1331-6.

48. Liebeskind DS, Tomsick TA, Foster LD, Yeatts SD, Carrozzella J, Demchuk AM, et al. Collaterals at angiography and outcomes in the Interventional Management of Stroke (IMS) III trial. Stroke; a journal of cerebral circulation. 2014:45:759-64.

49. Liebeskind DS, Jahan R, Nogueira RG, Zaidat OO, Saver JL, Investigators S. Impact of collaterals on successful revascularization in Solitaire FR with the intention for thrombectomy. Stroke; a journal of cerebral circulation. 2014:45:2036-40.

50. Singer OC, Berkefeld J, Nolte CH, Bohner G, Reich A, Wiesmann M, et al. Collateral vessels in proximal middle cerebral artery occlusion: the ENDOSTROKE study. Radiology. 2015;274:851-8.

51. Nambiar V, Sohn SI, Almekhlafi MA, Chang HW, Mishra S, Qazi E, et al. CTA collateral status and response to recanalization in patients with acute ischemic stroke. AJNR Am J Neuroradiol. 2014;35:884-90.

52. Albers GW, Thijs VN, Wechsler L, Kemp S, Schlaug G, Skalabrin E, et al. Magnetic resonance imaging profiles predict clinical response to early reperfusion: the diffusion and perfusion imaging evaluation for understanding stroke evolution (DEFUSE) study. Ann Neurol. 2006;60:508-17.

53. Cho SH, Kim DG, Kim DS, Kim YH, Lee CH, Jang SH. Motor outcome according to the integrity of the corticospinal tract determined by diffusion tensor tractography in the early stage of corona radiata infarct. Neurosci Lett. 2007:426:123-7.

54. Lindenberg R, Zhu LL, Ruber T, Schlaug G. Predicting functional motor potential in chronic stroke patients using diffusion tensor imaging. Hum Brain Mapp. 2012;33:1040-51

55. Puig J, Pedraza S, Blasco G, Daunis IEJ, Prados F, Remollo S, et al. Acute damage to the posterior limb of the internal capsule on diffusion tensor tractography as an early imaging predictor of motor outcome after stroke. AJNR Am J Neuroradiol. 2011;32:857-63.

56. Warach S, Latour LL. Evidence of reperfusion injury, exacerbated by thrombolytic therapy, in human focal brain ischemia using a novel imaging marker of early blood-brain barrier disruption. Stroke; a journal of cerebral circulation. 2004;35:2659-61.

57. Aviv Rl, d'Esterre CD, Murphy BD, Hopyan JJ, Buck B, Mallia G, et al. Hemorrhagic transformation of ischemic stroke: prediction with $C T$ perfusion. Radiology. 2009;250:867-77.

58. Ozkul-Wermester O, Guegan-Massardier E, Triquenot A, Borden A, Perot G, Gerardin E. Increased blood-brain barrier permeability on perfusion computed tomography predicts hemorrhagic transformation in acute ischemic stroke. Eur Neurol. 2014;72:45-53. 